\title{
Potential negative effects of groundwater dynamics on dry season convection in the Amazon River basin
}

\author{
Yen-Heng Lin ${ }^{1}$ Min-Hui Lo ${ }^{1}$ Chia Chou ${ }^{1,2}$
}

Received: 5 November 2014 / Accepted: 22 April 2015 / Published online: 5 May 2015

(C) The Author(s) 2015. This article is published with open access at Springerlink.com

\begin{abstract}
Adding a groundwater component to land surface models affects modeled precipitation. The additional water supply from the subsurface contributes to increased water vapor in the atmosphere, resulting in modifications of atmospheric convection. This study focuses on how groundwater dynamics affect atmospheric convection in the Amazon River basin (ARB) during July, typically the driest month. Coupled groundwater-land-atmosphere model simulations show that groundwater storage increases evapotranspiration rates (latent heat fluxes) and lowers surface temperatures, which increases the surface pressure gradient and thus, anomalous surface divergence. Therefore, the convection over the Southern Hemispheric ARB during the dry season becomes weaker when groundwater dynamics are included in the model. Additionally, the changes in atmospheric vertical water vapor advection are associated with decreases in precipitation that results from downwelling transport anomalies. The results of this study highlight the importance of subsurface hydrological processes in the Amazon climate system, with implications for precipitation changes during the dry season, observed in most current climate models.
\end{abstract}

Min-Hui Lo

minhuilo@ntu.edu.tw

Yen-Heng Lin

yheng@pie.com.tw

Chia Chou

chiachou@rcec.sinica.edu.tw

1 Department of Atmospheric Sciences, National Taiwan University, Taipei, Taiwan

2 Research Center for Environment Changes, Academia Sinica, Taipei, Taiwan
Keywords Groundwater - Amazon River basin . Moist static energy

\section{Introduction}

The need to incorporate groundwater hydrology in global land surface models is receiving increased attention (Liang et al. 2003; Yeh and Eltahir 2005; Niu et al. 2007; Fan et al. 2007; Lo et al. 2008, 2010; Campoy et al. 2013; Krakauer et al. 2013). Groundwater storage can affect atmospheric and terrestrial hydrological processes by affecting soil moisture profiles and evapotranspiration (ET) rates (Famiglietti and Wood 1994; Gutowski et al. 2002; Yeh and Famiglietti 2009). For example, partitioning precipitation into ET and runoff can be considerably improved after incorporating water table dynamics in land surface model parameterization (Yeh and Eltahir 2005). Hasler and Avissar (2007) mentioned that general circulation models (GCMs) often overestimate the water stress in tropical rain forests. After including groundwater storage in aquifers, simulated total land water storage anomalies (including soil water and groundwater) more closely matched those observed in the Gravity Recovery and Climate Experiment [GRACE, Tapley et al. (2004)] in regions where snow melt and frozen soils are not dominant (Niu et al. 2007). A study conducted using an observational data set including soil moisture, groundwater, and streamflow showed that groundwater storage can have a substantial impact on the rate of ET, especially during dry seasons in Illinois (Yeh and Famiglietti 2009). Based on extensive collections of groundwater well data sets, Fan et al. (2013) concluded that on a global basis, shallow groundwater influences approximately $27 \%$ of the global land area, including approximately $15 \%$ of groundwater-fed surface water regions. 
Groundwater storage can also influence climate at regional and global scales. Some studies (Anyah et al. 2008; Yuan et al. 2008; Jiang et al. 2009; Campoy et al. 2013) have shown that accounting for hydrological processes in aquifers and lower soil boundary conditions can alter simulated land-atmosphere feedbacks in regional and global climate models. Including a groundwater module in land surface models alters the modeled distribution of precipitation (Lo and Famiglietti 2011). Their results indicated that globally inhomogeneous changes in precipitation in the boreal summer, and tropical regions show a positive anomaly in the Northern Hemisphere and a negative anomaly in the Southern Hemisphere. In addition to directly supplying water to the soil, atmosphere, and surface water, groundwater storage may also modulate the timescales of terrestrial hydrological processes because of the long time scales involved. van den Hurk et al. (2005) found that the responses of the terrestrial hydrological cycle are usually too rapid in regional models because of insufficient land water storage. Similarly, Koutsoyiannis et al. (2007) showed that simulated runoff has a high temporal persistence when groundwater storage is incorporated into the runoff generation scheme. Groundwater storage can have nonlinear effects on the surface soil moisture persistence, depending on water table dynamics (Lo and Famiglietti 2010). Including a groundwater aquifer module to the Goddard Institute for Space Studies (GISS) ModelE general circulation model had a limited impact on mean climate, but affected the seasonality and interannual persistence of soil moisture and climate (Krakauer et al. 2013).

From a regional perspective, groundwater storage also plays a critical role in the hydrological cycle in the Amazon River basin (ARB), which contributes a substantial amount of water vapor to the atmosphere and fresh water discharge to the ocean. Because of the delayed response of groundwater to atmospheric forcing, groundwater storage can provide a buffer for the surface water dynamics in the Amazon River in dry seasons Miguez-Macho and Fan (2012a). Miguez-Macho and Fan (2012b) also suggested that accounting for shallow groundwater produces considerable differences in the simulated soil moisture over the ARB. The response of ET to groundwater depends on the seasonal amplitude of the atmospheric precipitation and temperature, and land surface conditions, resulting in a substantial increase in ET in the dry season. Using an observational dataset, Juárez et al. (2007) showed that, during the dry season, the deep soil provides a sufficient supply of water to account for ET because of the extensive and deep root system of trees in the ARB (da Rocha et al. 2009). Hydraulic redistribution (HR), a phenomenon of tree root redistributes soil water from wet to dry areas at night and normally redistributes the water from deep soil, where water was stored in raining season, to surface soil
(Lee et al. 2005). Lee et al. (2005) have shown that HR can influence ET and surface temperature in the dry season, because the redistribution of water enhances the transpiration and lowers the surface temperature.

Murthi et al. (2011) showed that the National Center for Atmospheric Research Community Atmosphere Model (CAM3) underestimates the precipitation in the Amazon. Most CMIP5 models [including NCAR Community Climate System Model version 4 (Gent et al. 2011)] also show the underestimated precipitation over tropical South America notwithstanding the season (Yin et al. 2013). In this study, we focus on how groundwater dynamics and land surface energy changes impact the precipitation. The extent to which groundwater affects the Amazonian climate system, especially during the dry seasons when groundwater has the most substantial impact on ET is unclear. According to Lo and Famiglietti (2011), groundwater storage can result in an asymmetric dipole of precipitation changes over northern South America, an opposite precipitation anomalies over the Northern and Southern Hemisphere of South America. However, the mechanism that controls the negative precipitation anomalies over south of the equator is not clearly identified. In addition, Lee et al. (2012) mentioned that model simulation without transpiration over tropical rainforests leads to less precipitation, but the variability of precipitation will increase, which means the extreme precipitation will get stronger. Harper et al. (2014) also showed that during dry periods in the Amazon, the unstressed soil moisture condition (wetter soil layer) may induce less precipitation over the Amazon. Based on the literature thus far, understanding the impact of groundwater storage on the changes in atmospheric conditions over the ARB using a fully coupled atmosphere-land-groundwater model could be an important addition to the already known science (i.e., the underestimated precipitation in GCMs) that is the main goal of this study.

\section{Model}

The coupled climate model used for this study was the NCAR Community Atmosphere Model, version 3.5 (CAM3.5). Substantial modifications and improvements to CAM3.0 are incorporated in CAM3.5. For details on the changes in the model, the reader is referred to Gent et al. (2009) and references therein. CAM3.5 includes the Community Land Model (CLM) version 3.5 (Oleson et al. 2008) coupled with an unconfined groundwater aquifer model (Niu et al. 2005, 2007). The groundwater recharge flux in CLM 3.5 (Niu et al. 2007; Oleson et al. 2008) is described by Darcy's law:

$$
\left(q=-k \frac{\partial\left(\psi=\psi_{m}+\psi_{g}\right)}{\partial z}\right),
$$


where $q$ is the soil water flux (negative upwards), $k$ is the hydraulic conductivity, $\psi$ is the hydraulic potential, and $z$ is the depth between the water table and the soil layer. The hydraulic potential can be separated into soil water potential $\left(\psi_{m}\right)$ and gravitational potential $\left(\psi_{g}\right)$. The reference level is in the soil surface so $\psi_{g}$ is equal to the depth $(-z)$.

Compared to vertical soil water flux computations in the CLM 3.0, the most significant modification of adding an unconfined aquifer model to the CLM 3.5 is the extra source of water from the groundwater. The water table is interactively linked to soil moisture model through the exchange of groundwater recharge (i.e., soil drainage flux) and capillary rise $\left(q_{m}=-k \frac{\partial \psi_{m}}{\partial z}\right)$ at the bottom of the soil column, in which there are 10 soil layers with increasing thickness from 0 to $3.43 \mathrm{~m}$ below the surface. The groundwater model utilized in this study is a simple unconfined aquifer system (without lateral groundwater flow and a confined aquifer), which is recognized as having interactions with the climate system (Yeh and Famiglietti 2009). Considering most of the current climate models, which lack any representation of groundwater processes, this study focused on the linkages between shallow unconfined groundwater and precipitation in the ARB rather than the development of a sophisticated groundwater model in the CLM.

The simulations used in this study were performed at the standard T85 resolution (approximately $1.4^{\circ} \times 1.4^{\circ}$ ) with 26 vertical hybrid coordinate levels. We used similar CLM setting with Lo and Famiglietti (2011), which was focused on global groundwater effect in boreal summer. The major model setting difference is that this study used a finer T85 resolution instead of T42. Furthermore, this study focused on exploring the mechanism of the circulation changes during the dry season over the Southern Hemispheric part of Amazon. Two online experiments using CAM3.5 were then done: (1) the no groundwater (NOGW) run and (2) the groundwater $(\mathrm{GW})$ run. In the NOGW run, the capillary flux from the aquifer to the soil model was inactive in the CLM3.5. In the GW run, the water table was interactively linked to the soil moisture model through the exchange of soil drainage flux and capillary rise at the bottom of the soil column. Other than the modification of capillary flux, the model configuration was kept the same between the two simulations. As a result, the impact of groundwater storage on precipitation could be identified based on the differences between the two experiments. These simulations were forced by the prescribed sea surface temperatures and sea ice concentrations (Hurrell et al. 2008).

Next, we evaluated the statistical significance of both simulations using the Student's $t$ tests with a $95 \%$ significance level. For detailed information on the experimental setup, the reader is referred to Lo and Famiglietti (2011). The simulation produced a global monthly output from
1871 to 1999 . To remove the effects of uncertain initial and boundary conditions, as well as the long persistence effect of the groundwater aquifer, the 1871-1949 period was treated as a spin-up, and the subsequent 50-year (19501999) simulations were used in the analysis. Although the analysis focused on July, when most of the Southern Hemispheric ARB is in the dry season, we also analyzed the combined period for June, July, and August (JJA), which showed similar results.

\section{Methodology}

\subsection{Vertically integrated water vapor budget}

The vertically integrated water vapor budget equation can be used to examine precipitation changes induced by groundwater dynamics:

$\left\langle\frac{\partial q}{\partial t}\right\rangle=E T-P-\langle\nabla \cdot(v q)\rangle$,

where $q$ is water vapor, $E T$ is evapotranspiration, $P$ is precipitation, $v$ is horizontal velocity, $-\nabla \cdot(v q)$ is the divergence of moisture flux, and \langle\rangle denotes mass integration throughout the troposphere, i.e., $\frac{1}{g} \int_{p_{s}}^{p_{t}}() d p$, where $g$ is gravity, $p_{t}$ is the pressure at the tropopause $(100 \mathrm{hPa}$ in this study), and $p_{s}$ is surface pressure. Because the pressure velocity is near zero at the surface and the tropopause (Tan et al. 2008), the divergence of moisture flux can be estimated as follows:

$-\langle\nabla \cdot(v q)\rangle \approx-\langle v \cdot \nabla q\rangle-\left\langle\omega \frac{\partial q}{\partial p}\right\rangle$,

where $\omega$ is pressure velocity, $-v \cdot \nabla q$ is the horizontal moisture advection, and $-\omega \frac{\partial q}{\partial p}$ can be regarded as the vertical moisture advection. The long-term averaged time derivation term $\left(\left\langle\frac{\partial q}{\partial t}\right\rangle\right)$ is insignificant, which is ignored here. Therefore, anomalies for the vertically integrated moisture budget equation can be written as (Chou and Neelin 2004; Chou et al. 2006)

$P^{\prime} \approx E T^{\prime}-\langle v \cdot \nabla q\rangle^{\prime}-\left\langle\omega \frac{\partial q}{\partial p}\right\rangle^{\prime}$,

where apostrophe ' represents anomalies caused by groundwater effects. The changes in vertical moisture advection can be further divided into two terms:

$-\left\langle\omega \frac{\partial q}{\partial p}\right\rangle^{\prime} \approx-\left\langle\bar{\omega} \frac{\partial q^{\prime}}{\partial p}\right\rangle-\left\langle\omega^{\prime} \frac{\overline{\partial q}}{\partial p}\right\rangle$,

where $\left({ }^{-}\right)$is the value from the control run, i.e., NOGW run, and ()$^{\prime}$ is anomalies. The first term on the right-hand side of Eq. (4) is associated with changes in water vapor, and is usually termed the thermodynamic component (Held 
and Soden 2006; Chou et al. 2009; Seager et al. 2010). The second term on the right-hand side of Eq. (4) is related to changes in pressure velocity, which is associated with atmospheric circulation, and is termed the dynamic component (Held and Soden 2006; Chou et al. 2009; Seager et al. 2010). In addition, we neglected the nonlinear term of $-\left\langle\omega^{\prime} \frac{\partial q^{\prime}}{\partial p}\right\rangle$ in this study because the changes were insignificant. Hence, anomalies for the vertically integrated moisture budget equation can be rewritten as follows:

$P^{\prime} \approx E T^{\prime}-\langle v \cdot \nabla q\rangle^{\prime}-\left\langle\bar{\omega} \frac{\partial q^{\prime}}{\partial p}\right\rangle-\left\langle\omega^{\prime} \frac{\overline{\partial q}}{\partial p}\right\rangle$

\subsection{Moist static energy}

The vertical profile of moist static energy (MSE or $h$ ) anomalies helps us analyze the moist static stability (Chou et al. 2013b). MSE is defined as

$M S E=h=C_{p} T+L_{v} q+g z$

where $C_{p}$ is the specific heat at constant pressure, $T$ is temperature, $L_{v}$ is the latent heat of vaporization at $0{ }^{\circ} \mathrm{C}, q$ is the specific humidity, $g$ is the gravitational acceleration, and $z$ is height.

\section{Results and discussions}

\subsection{Impacts of groundwater on land surface processes}

Figure 1 shows the anomalies (GW - NOGW) for soil moisture and surface temperature over the ARB in July. Groundwater can support root zone soil moisture, as shown in Fig. 1a. Soil moisture increased throughout the ARB, and Miguez-Macho and Fan (2012b) also indicated that increasing soil moisture can maintain high ET rates throughout the dry season to influence the water cycle in the Amazon. In our study, the increasing soil moisture further shows a decrease in surface temperature (Fig. 1b). The influence of groundwater dynamics on precipitation is shown in Fig. 2. The precipitation amount is significantly reduced over the Southern Hemispheric part of ARB, as shown in Fig. 2a. The precipitation ratios (Fig. 2b) clearly show less overall precipitation. This result suggests that groundwater plays an important role in the dry season precipitation.

The precipitation anomalies in July shown in Fig. 2a can be decomposed into $E T^{\prime},-\langle v \cdot \nabla q\rangle^{\prime},-\left\langle\bar{\omega} \frac{\partial q^{\prime}}{\partial p}\right\rangle$, and $-\left\langle\omega^{\prime} \frac{\overline{\partial q}}{\partial p}\right\rangle$ from the vertically integrated water vapor budget equation as shown in Fig. 3 (all terms are expressed in energy units, $\mathrm{W} \mathrm{m}{ }^{-2}$, and dots indicate significant changes for each variable). Figure 3a shows an increase in ET rate (in energy units, $\mathrm{W} \mathrm{m}^{-2}$ ), with the most significant changes in ET

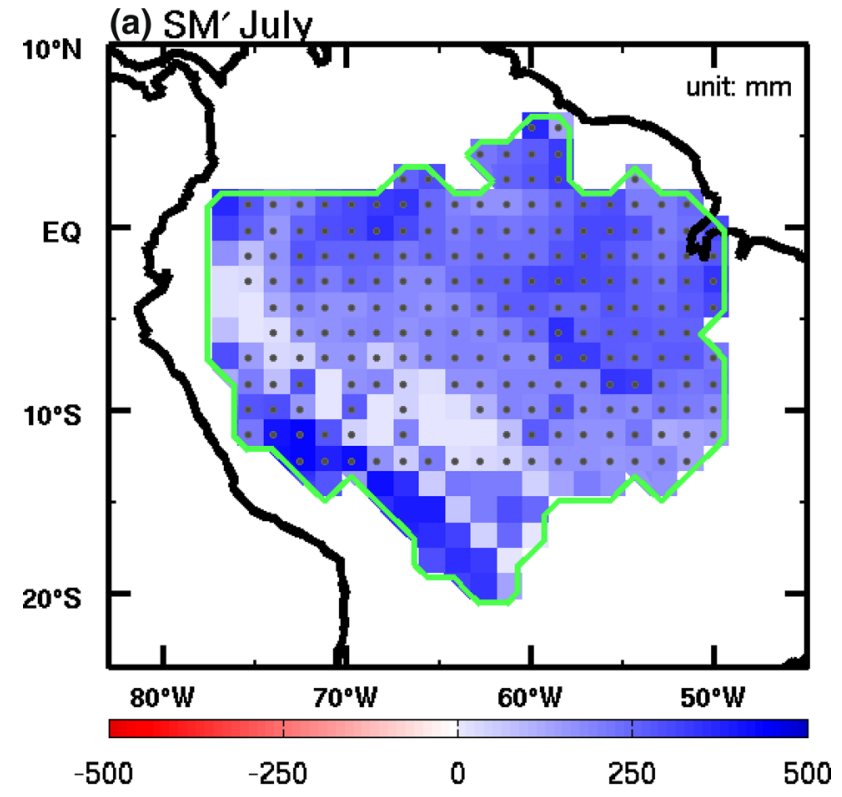

(b) TS' July

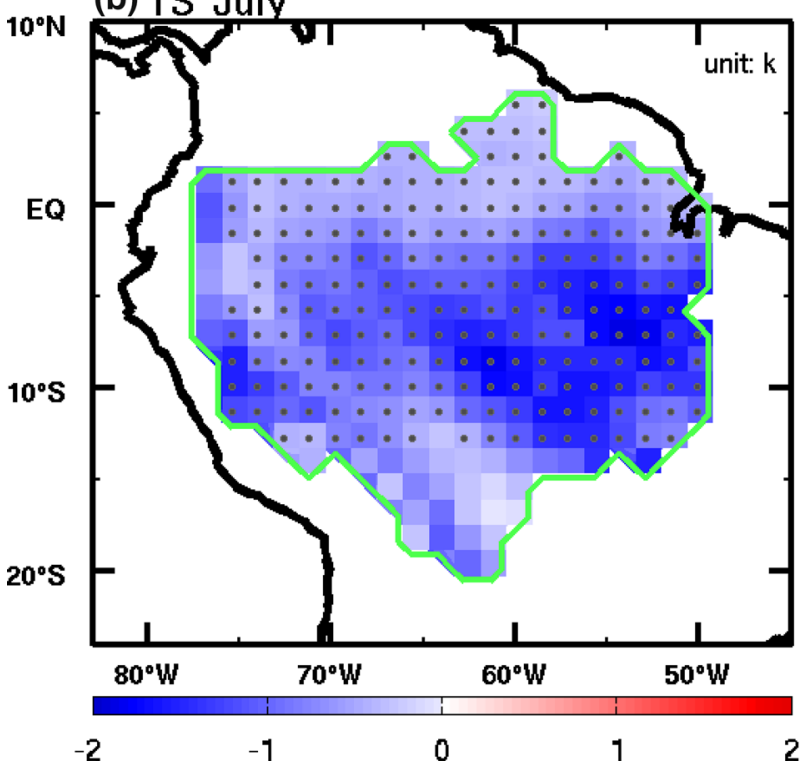

Fig. 1 The anomalies in a total soil moisture (mm, sum of ten soil layers, from surface to $3.43 \mathrm{~m}$ deep, in the CLM and $\mathbf{b}$ surface temperature $(\mathrm{K})$. Statistically significant results are dotted

rates occurring over the eastern ARB. This result is consistent with the groundwater modeling experiment conducted by Miguez-Macho and Fan (2012b). They showed that an increase in latent heat fluxes causes a loss of energy for land surface, so the surface temperature decreases. However, this does not indicate that ET significantly changed with changes in soil moisture. That depends on whether the region of increased soil moisture is located over a soilwater-limited or energy-limited region (Koster et al. 2004). 


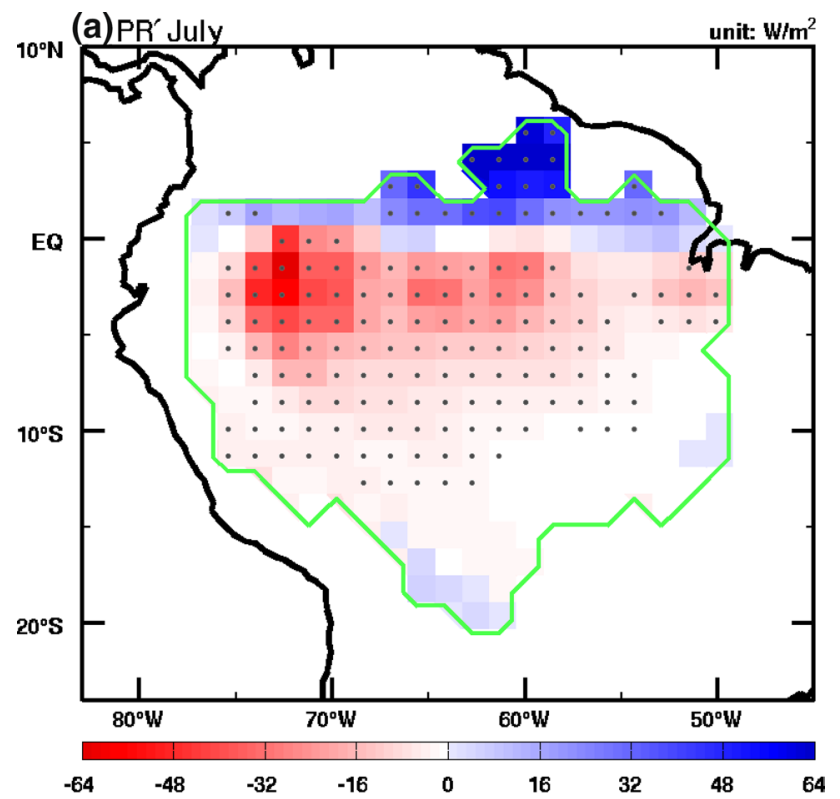

(b)PR'Ratio July

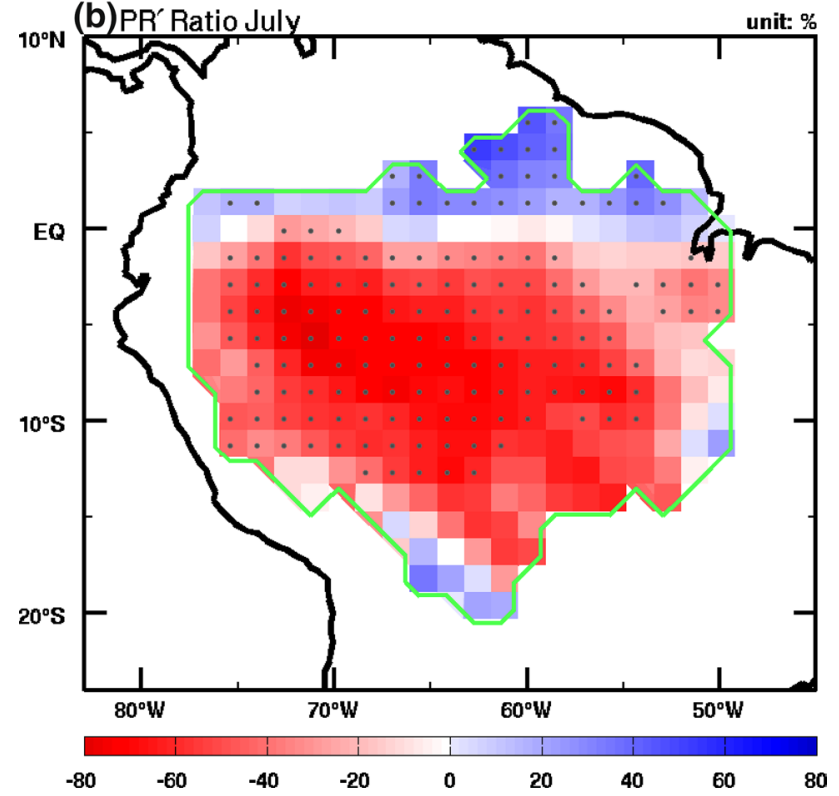

Fig. 2 Precipitation a anomalies $\left(\mathrm{W} \mathrm{m}^{-2}\right)$ and $\mathbf{b}$ anomalies ratio (\%, divided by the NOGW run). Statistically significant results are dotted

Although ET rates increase after including a groundwater interaction component in the $\mathrm{GW}$ run, providing more water vapor into the low level troposphere, the precipitation amount is significantly reduced over the Southern Hemispheric part of ARB. As a result, not only does groundwater provide more water vapor into the atmosphere, it also induces changes in atmosphere convection and stability that tend to influence the precipitation. A further analysis of Eq. 5 shows that the anomalous horizontal moisture advection term had a less clear pattern (Fig. 3b). The anomalous thermodynamic component of the vertical moisture advection term (Fig. 3c) shows a similar pattern to the anomalous dynamic component of the vertical moisture advection (Fig. 3d), but with opposite signs and much weaker amplitudes. As shown in Fig. 3d, the anomalous dynamic component of the vertical moisture advection term matched the patterns of precipitation anomalies in July (Fig. 2a) both in space and magnitude, except the downstream ARB region. The anomalous dynamic component of downstream ARB region was compensated by the ET anomalies. Overall, the analysis of the vertically integrated water budget equation in the atmosphere suggests that the reduced precipitation is associated with weaker convection (reduced dynamic component of the vertical moisture advection term) in the simulations with the groundwater dynamics.

\subsection{Impacts of groundwater on the atmospheric vertical velocity}

Because changes in the dynamic component of vertical moisture advection (Fig. 3d) resulted from changes in pressure velocity, Fig. 4 further shows the pressure velocity $\left(\mathrm{Pa} \mathrm{s}^{-1}\right.$, negative indicates upward motion) anomalies at $925,850,700$, and $500 \mathrm{hPa}$ in July. A significant decline in vertical velocity exists in the lower troposphere (below $700 \mathrm{hPa}$ ), consistent with the decreased anomalous dynamic component of the vertical moisture advection term shown in Fig. 3d. The anomalous subsidence in the lower troposphere is also consistent with the $925 \mathrm{hPa}$ divergence anomalies (vectors) shown in Fig. 5. Moreover, it is evident in Fig. 5 that the anomalous divergence coincides well with high surface pressure anomalies (shaded) as well as the anomalous pressure gradient. Additionally, the surface pressure anomalies seem to agree with the surface cooling anomalies shown in Fig. 1b. In other words, the reduced convection can be caused by a decrease in surface temperature, which enhances the surface pressure gradient and further induces the anomalous low-level divergence.

Figure 6 shows zonally (from $72 \mathrm{~W}$ to $55 \mathrm{~W}$, as indicated by the red outlined box in Fig. 4d) averaged mean pressure velocity from $20 \mathrm{~S}$ to $13 \mathrm{~N}$ for July. The region south of the equator, which is our target domain in this study, showed anomalous downward motion over the lower troposphere at approximately $925-750 \mathrm{hPa}$. This anomalous vertical motion is opposite the climatological upward motion, and the mean ascending motion is therefore reduced. As described in Figs. 4 and 5, the surface cooling in the GW run increased the surface pressure gradient and led to anomalous surface divergence and downward motion anomalies.

Figure 6 also shows anomalous upward motion over the region north of the equator, during the wet season. This anomalous vertical motion, on the other hand, is in the 
(a) ET' July

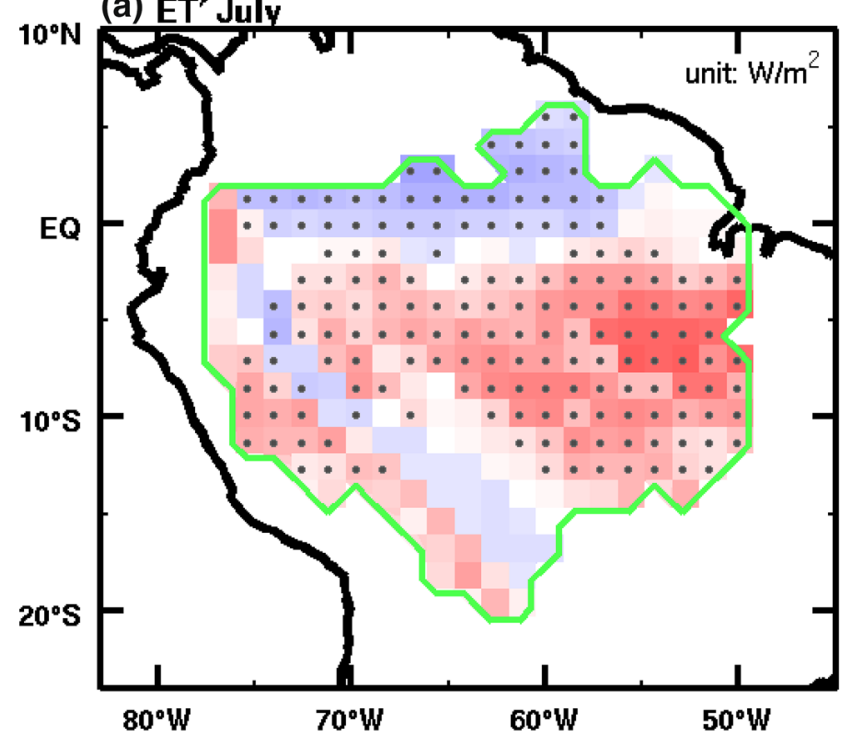

(c) $-(\bar{W}$ dq $)$ July

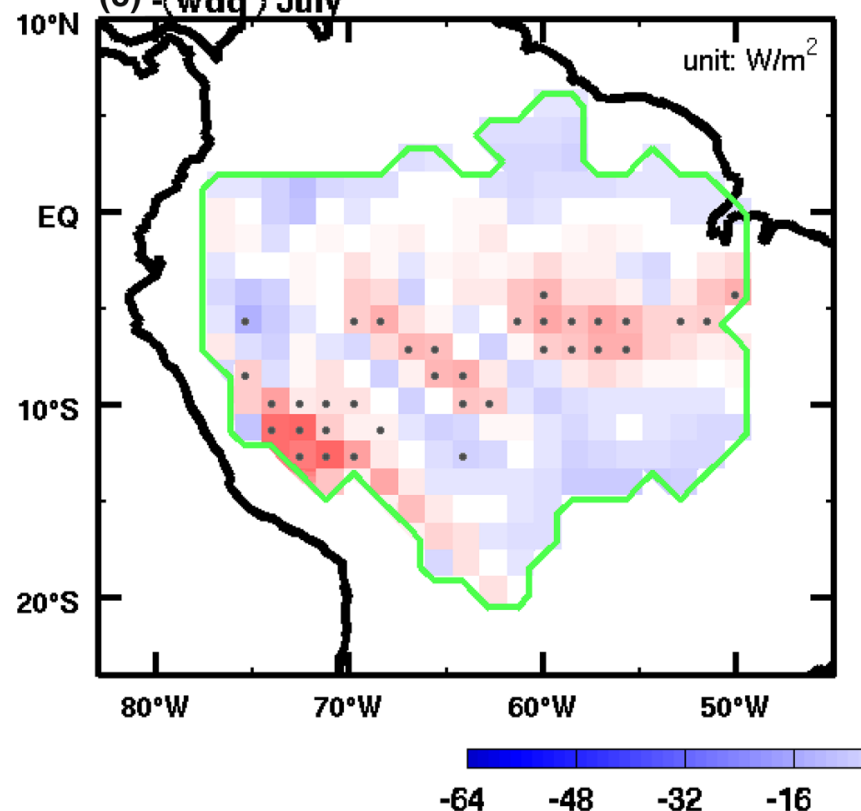

(b) $-(\mathrm{V} \cdot \nabla \mathbf{q})^{\prime}$ July

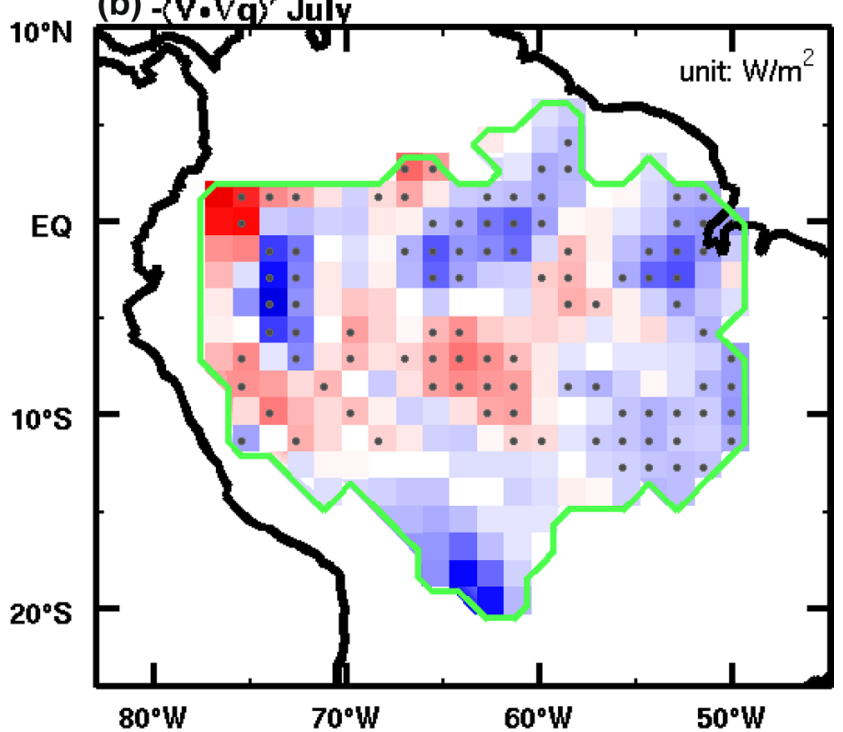

(d) $-\left(W^{\prime}\right.$ dg) July

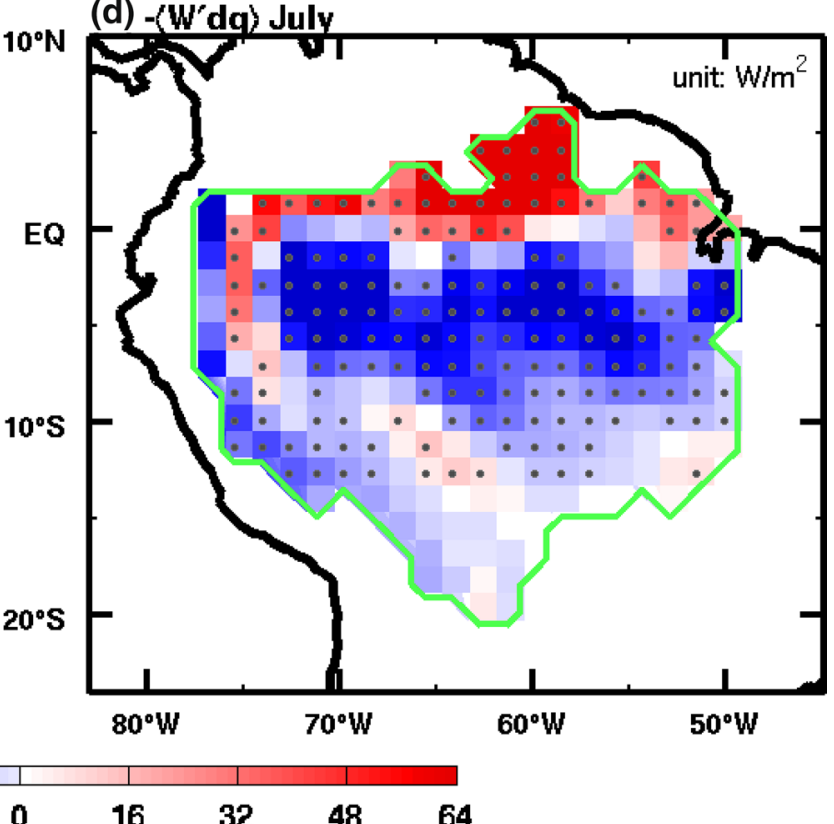

Fig. 3 Vertically integrated moisture budget anomalies in July. a Evapotranspiration ( $\mathrm{W} \mathrm{m} \mathrm{m}^{-2}$ ), b horizontal moisture advection $\left(\mathrm{W} \mathrm{m}^{-2}\right)$, $\mathbf{c}$ thermodynamic component of vertical moisture advection
( $\mathrm{W} \mathrm{m}^{-2}$ ), and $\mathbf{d}$ dynamic component of vertical moisture advection $\left(\mathrm{W} \mathrm{m}^{-2}\right)$. Statistically significant results are dotted

area when the northern South America is in wet season. The results of the present study offer a possible mechanism to account for the precipitation changes in the Southern Hemispheric part of ARB during the dry season. Changes in precipitation over the southern ARB reveal a phenomenon that makes the dry season even drier. This phenomenon also occurs over Orinoco and the region north of the ARB in January. Furthermore, by analyzing the vertically integrated water vapor budget equation, we determined that the dynamic components (changes in $\omega$, i.e., $-\left\langle\omega^{\prime}\left(\frac{\partial \bar{q}}{\partial p}\right)\right\rangle$ ) 


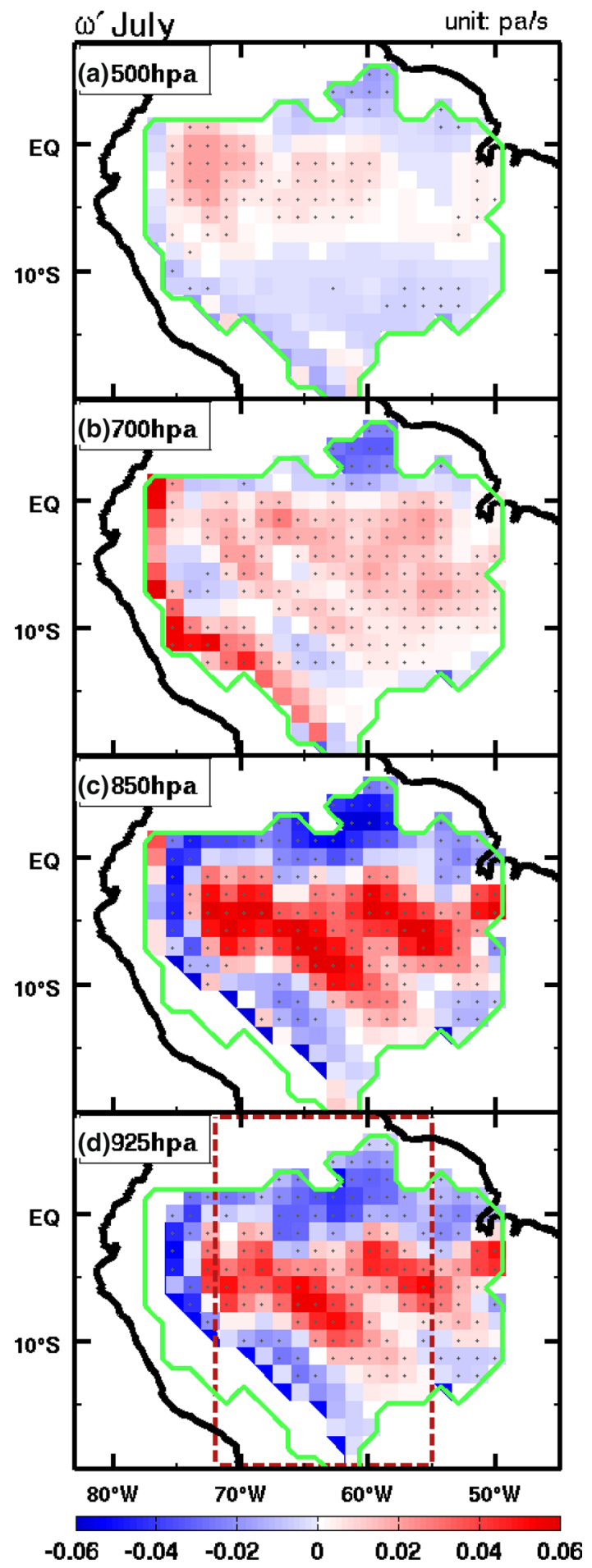

Fig. 4 Pressure velocity anomalies $\left(\mathrm{Pa} \mathrm{s}^{-1}\right)$ at a 500, b 700, c 850, and $\mathbf{d} 925 \mathrm{hPa}$. Statistically significant results are dotted. The white area near the west boundary of ARB in $\mathbf{c}$ and $\mathbf{d}$ is the mountain

rather than thermodynamic components (changes in $q$, i.e., $\left.-\left\langle\bar{\omega}\left(\frac{\partial q}{\partial p}\right)^{\prime}\right\rangle\right)$ of vertical water vapor advection are more associated with the changes in precipitation.
The decrease in surface temperature could also increase atmospheric stability, and reduce convection. As presented in Fig. 7, the vertical profile of changes in MSE (Eq. 6) and its decomposition averaged inside the Southern Hemispheric part of ARB have the consistent response in the decreased July precipitation. The term of $C_{p} T$ tends to stabilize the atmosphere, i.e., $\frac{d T^{\prime}}{d z}>0$, especially between 850 and $700 \mathrm{hPa}$. The $L_{v} q$ term, on the other hand, destabilizes the atmosphere, i.e., $\frac{d q^{\prime}}{d z}<0$, between 925 and $700 \mathrm{hPa}$ in particular. Overall, due to the strong surface cooling, the MSE decreases throughout the lower troposphere; however, the vertical gradient of MSE $\left(\frac{d h^{\prime}}{d z}\right)$ shows a relatively complicated profile. Below $750 \mathrm{hPa}$, the atmosphere in fact becomes more unstable because of the contribution from the vertical structure of water vapor (the higher water vapor near the surface from the excess ET and the lower water vapor above $800 \mathrm{hPa}$ ). The MSE in this study presents no consistent effects between upper (above $750 \mathrm{mb}$ ) and lower (below $750 \mathrm{mb}$ ) atmosphere. In the lower level, the surface cooling effect is stronger than the moistening effect. The positive surface pressure anomalies due to cold surface present critical evidence in affecting and inhibiting the convection in the Southern Hemispheric ARB in July. Furthermore, the surface net radiation increases (Fig. 8a) resulting from weaker convection and less cloud cover (Fig. 8b) in the GW run; however, the higher net radiation does not cause higher temperature. It suggests that changes in land surface temperature principally refer to the ET increases from adding the groundwater dynamics.

\subsection{Idealized simulation with decreases in surface temperature}

We confirm these processes (cooling, changes of pressure, and then convection) by further conducting an idealized simulation with arbitrarily reduced surface temperature over the ARB (NOGW_COOL run). This NOGW_COOL run has the same model configuration as the NOGW run, except that surface temperature within the ARB is reduced by about $1 \mathrm{~K}$ per monthly mean in July to explore the role of surface cooling effect. The results of NOGW COOL - NOGW show a reduction of ET (Fig. 9d) most likely due to a surface cooling (Fig. 9a) and the declined precipitation (Fig. 9b). On the contrary, surface pressure increases (Fig. 9c), which is induced by the cooler surface (Fig. 9a). The positive pressure anomalies are consistent with surface divergence (Fig. 9c), which reduces convection and the corresponding precipitation. This comparison further suggests that surface pressure anomalies due to surface cooling plays an important role in atmospheric stability in driving precipitation changes over the ARB region during the dry season. 
Fig. 5 The anomalous surface pressure $(\mathrm{hPa})$, and the vectors indicate anomalous divergent winds $\left(\mathrm{m} \mathrm{s}^{-1}\right)$ at $925 \mathrm{hPa}$. The white area near the west boundary of ARB is the mountain

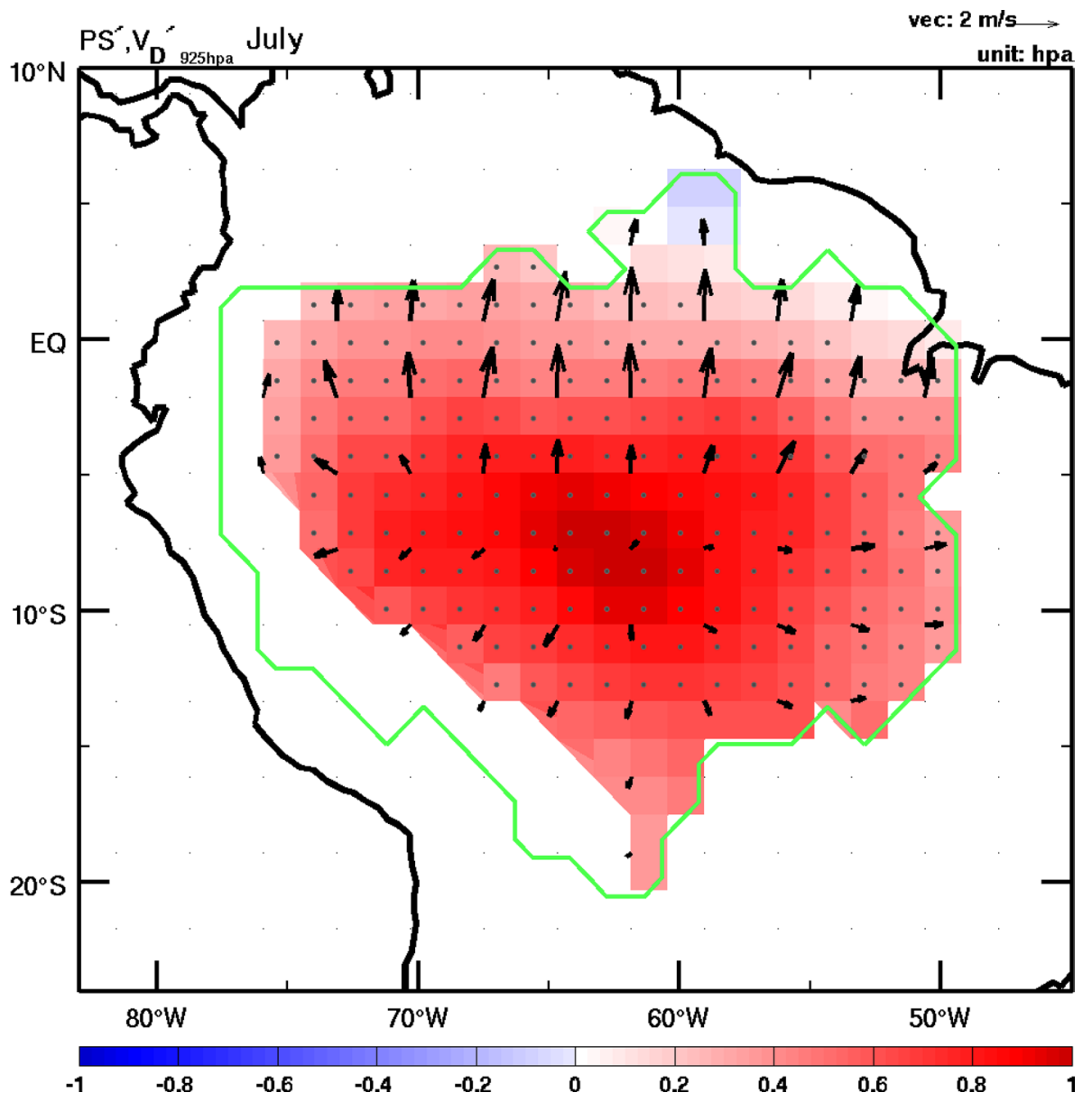

Next, the corresponding (NOGW_COOL - NOGW) vertical profile (with the same domain average as Fig. 7) of MSE anomalies $\left(h^{\prime}\right)$ in July is shown in Fig. 10. The result here suggests stabilization of the atmosphere, i.e., $\frac{d h^{\prime}}{d z}>0$. The positive vertical gradient of MSE is due to changes in both moisture $\left(\frac{d q^{\prime}}{d z}\right)$ and temperature $\left(\frac{d T^{\prime}}{d z}\right)$. Furthermore, both atmospheric temperature and moisture from the cooler surface show negative contributions to the MSE, i.e., $T^{\prime}<0$ and $q^{\prime}<0$. Comparing the results shown in Fig. 10 with the pattern shown in Fig. 7, the changes in dry static stability $\left(\frac{d T^{\prime}}{d z}+g z\right)$ in the lower troposphere are consistent for both cases, while the moist static stability $\left(\frac{d h^{\prime}}{d z}\right)$ show only minor difference in the lower troposphere due to the water vapor supply by groundwater component. Both dry and moist static stability show weakened convection and reduced precipitation.

\subsection{Discussions}

Most current climate models lack the representation of groundwater dynamics. After considering groundwater dynamics in the land surface model, we show that the dry season might become drier or, conversely, current model predictions without groundwater dynamics might underestimate the dry conditions in the ARB. While results shown in this study are based on the NCAR CAM + CLM, future tests using different models (such as NASA GISS model (Krakauer et al. 2013) and ORCHIDEE land surface model (Campoy et al. 2013), in which groundwater model has been incorporated to a GCM recently) are necessary to isolate the issue of model's uncertainty and dependency.

Under global warming, Chou and Lan (2012) and Chou et al. (2013a) indicated that the seasonal range of precipitation tends to increase; specifically, wet seasons become wetter and dry seasons become drier. Their studies indicated that the thermodynamics component (the increase in water vapor caused by global warming) dominates the changes in the annual precipitation range from a global point of view. Although groundwater can increase water vapor in the low troposphere, the resulting lower temperature plays an important role in affecting the low troposphere convection. It is crucial to understand changes in precipitation patterns when considering both the groundwater interactions (increase in water vapor but decrease in surface and low level troposphere temperature) and global warming (increase in both water vapor and temperature). 
Fig. 6 The zonally averaged mean pressure velocity. The shading is the climatology in the NOGW run, and the contour and vector show the differences between GW and NOGW runs (shading positive indicates downward motion, and negative indicates upward motion) and anomalous pressure velocity (contours dashed line is negative and indicates upward anomalies, $\mathrm{Pa} \mathrm{s}^{-1}$ ). The vectors indicate anomalous winds for the meridional components $v^{\prime}$ $(\mathrm{m} / \mathrm{s})$ and $\omega^{\prime * 100}\left(10^{-2} \mathrm{~Pa} \mathrm{~s}^{-1}\right)$

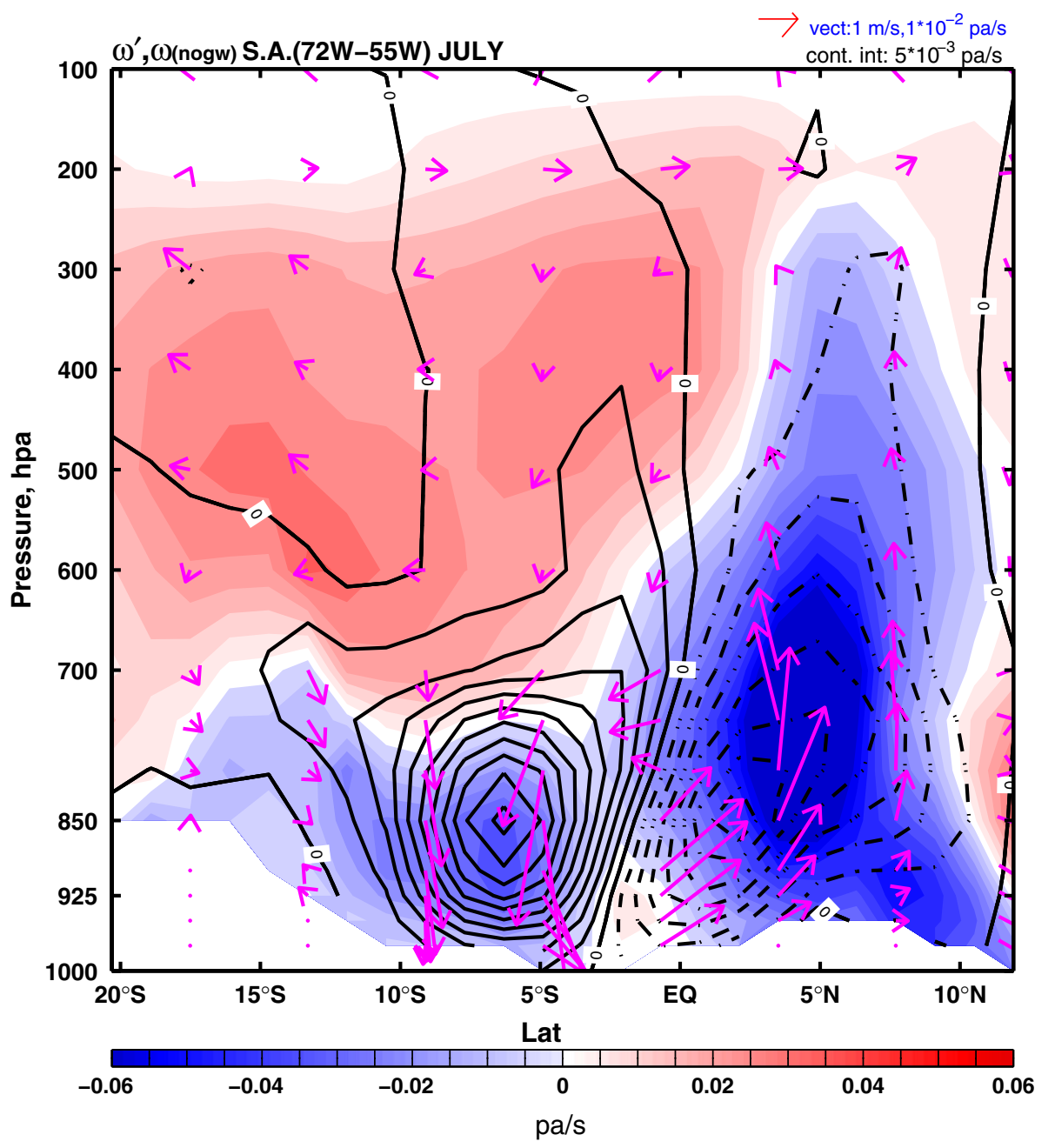

In addition, under weak synoptic-scale forcing, Negri et al. (2004) found precipitation over deforested areas could be larger than the high-density forest regions in the dry season. This conclusion was based on satellite observations showing less available ET with larger convergence (the opposite effect of adding the groundwater dynamics in the land surface model). On the other hand, model simulations show that deforestation can cause less ET and higher temperature, and decrease rainfall in dry season (Lejeune et al. 2014; da Silva et al. 2008; Lawrence and Vandecar 2015). Deforestation can also extend the dry season and have delayed onset of raining season (Costa and Pires 2010; Fu and Li 2004). Moreover, analysis from observational data also shows that deforestation area presents a stable environment in dry season, because the drier atmosphere reduces the convective available potential energy (CAPE) (Lejeune et al. 2014; Wang et al. 2009). However, in this study, the CAPE decreases because of stronger surface cooling effect compared to the moistening effect (Fig. 7). Hence, it will be interesting to explore what the combined effects of both groundwater and deforestation are on convection over the ARB as well, especially within the intense deforestation in the Amazon in the past couple decades.

\section{Conclusions}

In this study, groundwater maintains high water content in soil, increasing the ET rates (latent heat fluxes) in the dry season, which results in surface cooling. The decrease in land surface temperature increases the surface pressure gradient; hence, a subsidence anomaly forms in the lower troposphere. The velocity potential anomalies also confirm that in the lower troposphere, a divergence center exists over the region where the surface temperature decreases most. As a result, groundwater dynamics influence the dry season precipitation by changes in soil moisture that induces higher ET. The increase in ET causes the decline of surface temperature, which results in an anomalous low level divergence and further weakens convection in the low troposphere. 


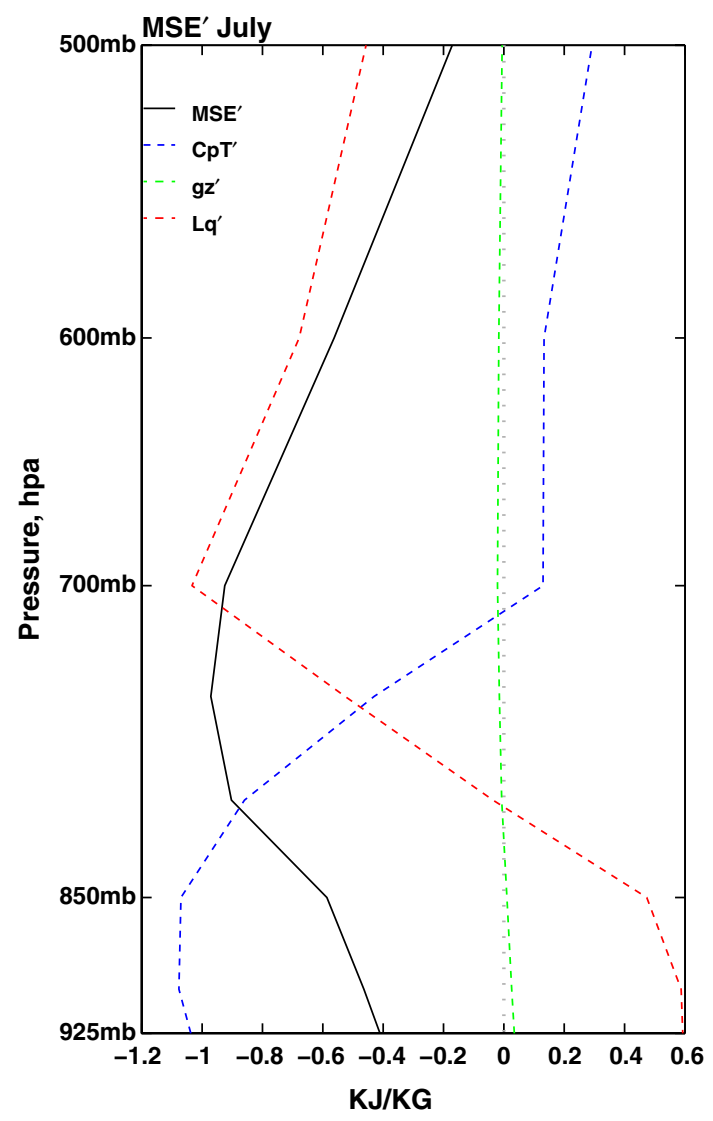

Fig. 7 Vertical profile of changes (GW - NOGW) in moist static energy (MSE, $\mathrm{KJ} \mathrm{Kg}^{-1}$ ) and its decomposition (i.e., $\mathrm{C}^{*} \mathrm{~T}, \mathrm{~g}^{*} z$, and $\left.\mathrm{L} v^{*} \mathrm{q}\right)$ averaged for the Southern Hemispheric ARB

These findings are similar to the results from a recent study by Harper et al. (2014) but with different mechanisms. Harper et al. (2014) showed that during the average dry season, the land surface temperature can be reduced with the unstressed (with enhanced root water access) land surface model, which causes the atmosphere to become more stable and less precipitation occurs. In this study, we also find the reduction of precipitation with wetter soil (with groundwater storage) condition over the dry season of ARB; as opposed to changes in stability, the surface cooling from the groundwater interactions induced an increase in the surface pressure gradient and an anomalous low level divergence, resulting the weaker convection. The changes in atmospheric stability shown in Fig. 7 in fact shows a more unstable atmosphere below $750 \mathrm{hPa}$, indicating the importance of the pressure velocity anomalies shown in Fig. 6 in reducing the convection.

Finally, Lo and Famiglietti (2011) showed that a positive precipitation anomaly exists over the northern ARB (wet hemisphere, during June, July, and August) in simulations considering groundwater dynamics. They attributed the higher precipitation to an increase in water vapor in the (a) NET Radiation' July

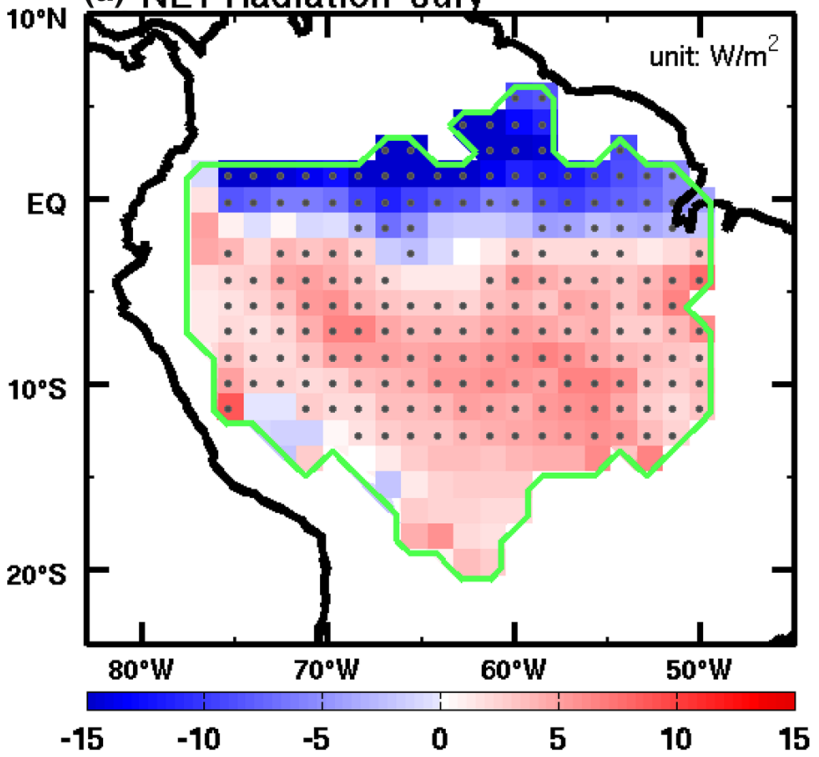

(b) Cloud Cover' July

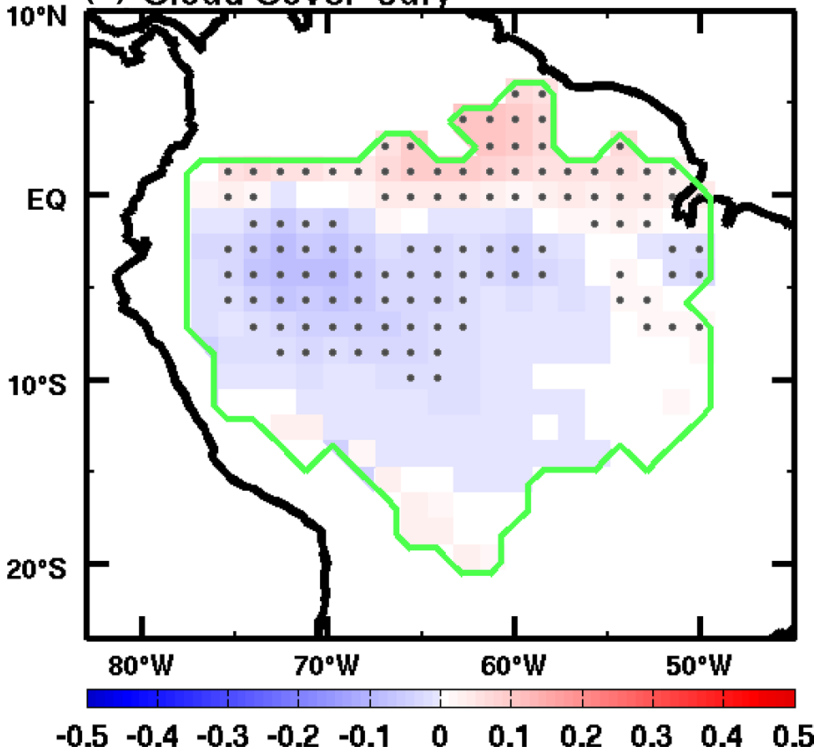

Fig. 8 The differences (NOGW_COOL - NOGW) in a surface net radiation $\left(\mathrm{W} \mathrm{m}^{-2}\right)$ and $\mathbf{b}$ total cloud cover. Statistically significant results are dotted

lower troposphere, which results in greater vertical moisture transport. This process enhances convection, causing more precipitation to occur over regions where precipitation amounts are already climatologically high. By contrast, our study additionally suggests that although extra water vapor in lower troposphere is supplied from groundwater, surface cooling, resulting from an increase in ET rates causes the weaker convection in the southern of ARB in the dry season. The positive precipitation anomaly in Northern Hemispheric ARB, may also be partially caused 
(a) TS'(NogwCool - NOGW) July

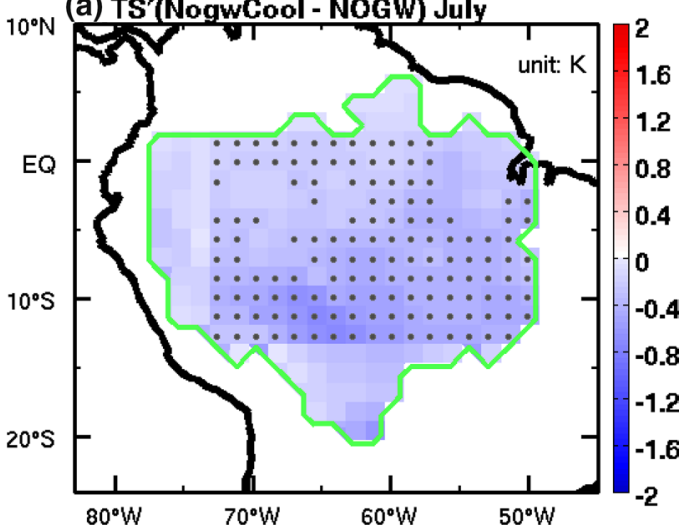

(b) PR' (NogwCool - NOGW) July

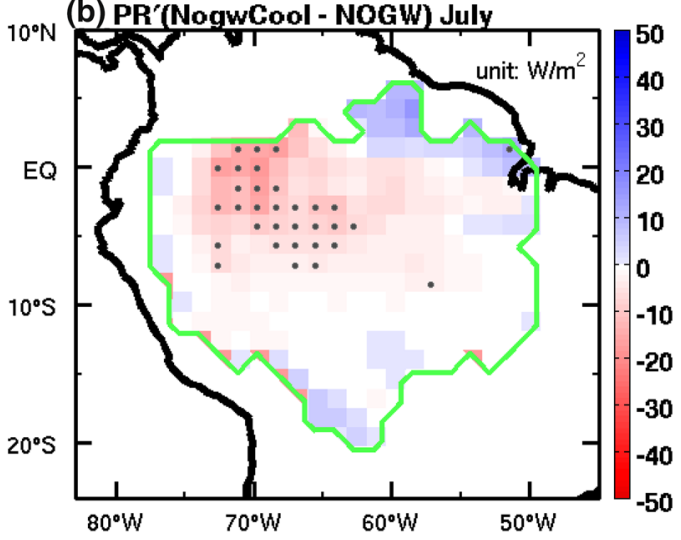

(c) PS', Vo'925hpa(NogwCool - NOGW) July

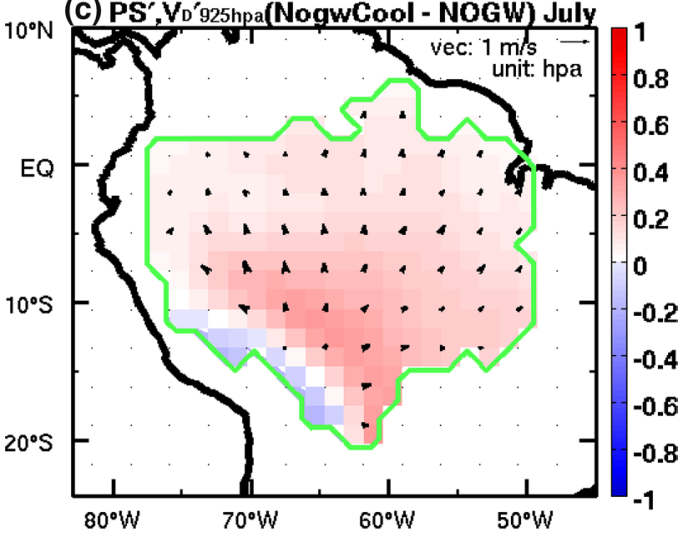

(d) ET'(NogwCool - NOGW) July

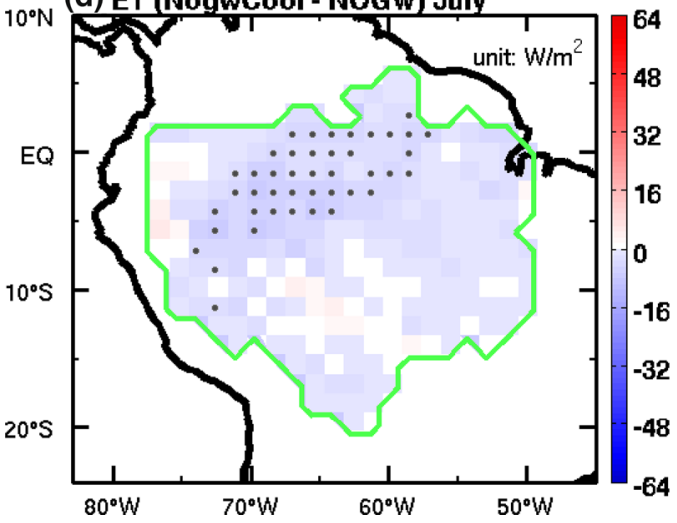

Fig. 9 The differences (NOGW_COOL - NOGW) in a surface temperature $(\mathrm{K})$, b precipitation $\left(\mathrm{W} \mathrm{m}^{-2}\right)$, c surface pressure $(\mathrm{hPa})$ and $925 \mathrm{hPa}$ divergent wind $\left(\mathrm{m} \mathrm{s}^{-1}\right)$, and $\mathbf{d}$ Evapotranspiration $\left(\mathrm{W} \mathrm{m}^{-2}\right)$. Statistically significant results are dotted

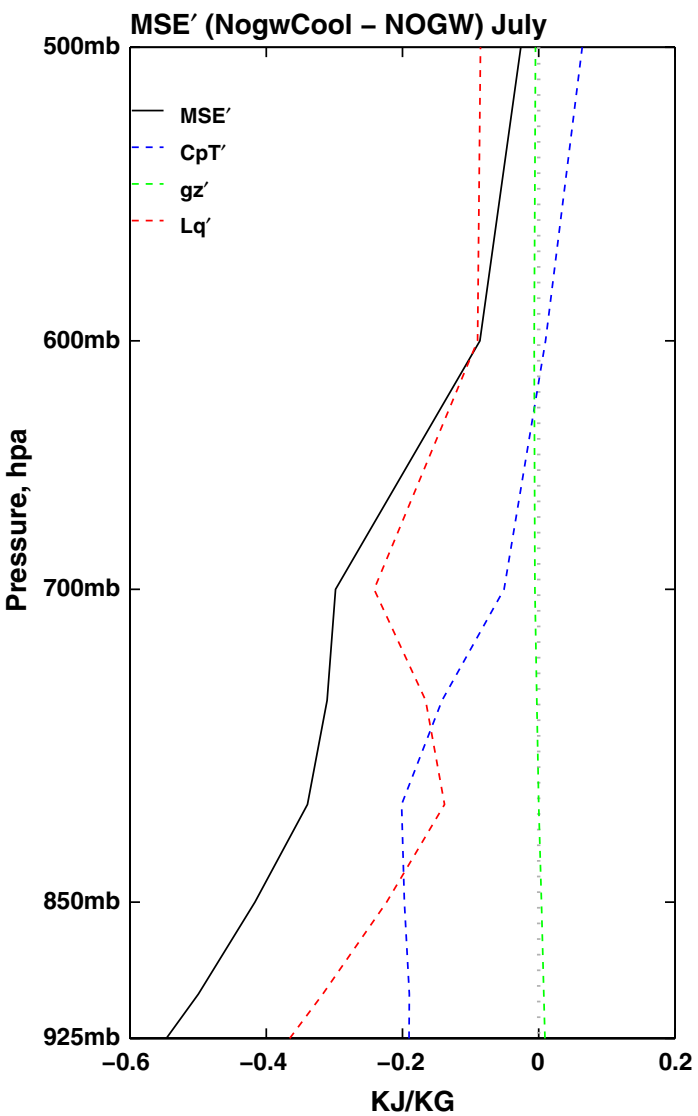

Fig. 10 Vertical profile of changes (NOGW_COOL - NOGW) in moist static energy (MSE, $\mathrm{KJ} \mathrm{Kg}^{-1}$ ) and its decomposition (i.e., $\mathrm{C} p^{*} \mathrm{~T}, \mathrm{~g}^{*} z$, and $\left.\mathrm{L} v^{*} \mathrm{q}\right)$ averaged for the Southern Hemispheric ARB

by the local circulation changes induced by the downward motion in the south and it should be confined at above $700 \mathrm{hPa}$, where is dominated by climatological descents. However, the groundwater dynamics are prescribed in the land surface model globally, and the changes in circulation and the supply of water vapor from groundwater are not isolated locally, different factors will influence them. Therefore, the relationship between the positive precipitation anomaly over the north and the negative precipitation anomaly over the south when considering groundwater dynamics in the land surface model requires further investigation.

Acknowledgments Funding was provided by the MOST-104-2923M-002-002-MY4 to National Taiwan University, and provided by MOST-100-2119-M-001-029-MY5. 
Open Access This article is distributed under the terms of the Creative Commons Attribution 4.0 International License (http://creativecommons.org/licenses/by/4.0/), which permits unrestricted use, distribution, and reproduction in any medium, provided you give appropriate credit to the original author(s) and the source, provide a link to the Creative Commons license, and indicate if changes were made.

\section{References}

Anyah RO, Weaver CP, Miguez-Macho G, Fan Y, Robock A (2008) Incorporating water table dynamics in climate modeling: 3. Simulated groundwater influence on coupled land-atmosphere variability. J Geophys Res 113:D07103. doi:10.1029/2007JD009087

Campoy A, Ducharne A, Cheruy F, Hourdin F, Polcher J, Dupont JC (2013) Response of land surface fluxes and precipitation to different soil bottom hydrological conditions in a general circulation model. J Geophys Res Atmos 118(10):725-739. doi:10.1002/jgrd.50627

Chou C, Lan CW (2012) Changes in the annual range of precipitation under global warming. J Clim 25:222-235. doi:10.1175/ JCLI-D-11-00097.1

Chou C, Neelin JD (2004) Mechanisms of global warming impacts on regional tropical precipitation. J Clim 17:2688-2701

Chou C, Neelin JD, Tu JY, Chen CT (2006) Regional tropical precipitation change mechanisms in ECHAM4/OPYC3 under global warming. J Clim 19:4207-4223. doi:10.1175/JCLI3858.1

Chou C, Nellin JD, Chen CA, Tu JY (2009) Evaluating the "rich-getricher" mechanism in tropical precipitation change under global warming. J Clim 22:1982-2005. doi:10.1175/2008JCLI2471.1

Chou C, Chiang JCH, Lan CW, Chung CH, Liao YC, Lee CJ (2013a) Increase in the range between wet and dry season precipitation. Nat Geosci 6:263-267. doi:10.1038/NGEO1744

Chou C, Wu TC, Tan PH (2013b) Changes in gross moist stability in the tropics under global warming. Clim Dyn 41:2481-2496. doi:10.1007/s00382-013-1703-2

Costa M, Pires G (2010) Effects of Amazon and Central Brazil deforestation scenarios on the duration of the dry season in the arc of deforestation. Int J Climatol 30(13):1970-1979

da Rocha HR, Manzi AO, Cabral OM, Miller SD, Goulden ML, Saleska SR, R-Coupe N, Wofsy SC, Bormal LS, Artaxo P, Vourlitis G, Nogueira JS, Cardoso FL, Nobre AD, Kruijt B, Freitas HC, von Randow C, Aguiar RG, Maia JF (2009) Patterns of water and heat flux across a biome gradient from tropical forest to savanna in Brazil. J Geophys Res 114:G00B12. doi:10.1029/ 2007JG000640

da Silva R, Werth RD, Avissa R (2008) Regional impacts of future land-cover changes on the Amazon basin wet-season climate. J Clim 21(6):1153-1170

Famiglietti JS, Wood EF (1994) Multi-scale modeling of spatiallyvariable water and energy balance processes. Water Resour Res 30(11):3061-3078

Fan Y, Miguez-Macho G, Weaver CP, Walko R, Robock A (2007) Incorporating water table dynamics in climate modeling: 1 . Water table observations and equilibrium water table simulations. J Geophys Res Atmos 112:D10125. doi:10.1029/2006JD008111

Fan Y, Li H, Miguez-Macho G (2013) Global patterns of groundwater table depth. Science 339:940-943. doi:10.1126/science.1229881

Fu R, Li W (2004) The influence of the land surface on the transition from dry to wet season in Amazonia. Theor Appl Climatol 78(1-3):97-110

Gent PR, Yeager SG, Neale RB, Levis S, Bailey DA (2009) Improvements in a half degree atmosphere/land version of the CCSM. Clim Dyn 34:819-833
Gent PR et al (2011) The community climate system model version 4 . J. Clim 24:4973-4991. doi:10.1175/2011JCLI4083.1

Gutowski WJ Jr, Vörösmarty CJ, Person M, Ötles Z, Fekete B, York J (2002) A coupled land-atmosphere simulation program (CLASP): calibration and validation. J Geophys Res Atmos 107:4283. doi:10.1029/2001JD000392

Harper A, Baker IT, Denning AS, Randall DA, Dazlich D, Branson M (2014) Impact of evapotranspiration on dry season climate in the Amazon forest. J Clim 27:574-591. doi:10.1175/ JCLI-D-13-00074.1

Hasler N, Avissar R (2007) What controls evapotranspiration in the Amazon basin? J Hydrol 8:380-395. doi:10.1175/JHM587.1

Held IM, Soden BJ (2006) Robust responses of the hydrological cycle to global warming. J Clim 19(21):5686-5699. doi:10.1175/ JCLI3990.1

Hurrell JW, Hack JJ, Shea D, Caron JM, Rosinski J (2008) A new sea surface temperature and sea ice boundary dataset for the community atmosphere model. J Clim 21:5145-5153. doi:10.1175/ 2008JCLI2292.1

Jiang X, Niu GY, Yang ZL (2009) Impacts of vegetation and groundwater dynamics on warm season precipitation over the central United States. J Geophys Res Atmos 114:D06109. doi:10.1029 /2008JD010756

Juárez RIN, Hodnett MG, Fu R, Goulden ML, von Randow C (2007) Control of dry season evapotranspiration over the amazonian forest as inferred from observations at a Southern Amazon forest site. J Clim 20:2827-2839. doi:10.1175/JCLI4184.1

Koster RD, Dirmeyer PA, Guo Z, Bonan G, Chan E, Cox P, Gordon CT, Kanae S, Kowalczyk E, Lawrence D, Liu P, Lu CH, Malyshev S, McAvaney B, Mitchell K, Mocko D, Oki T, Oleson K, Pitman A, Sud YC, Taylor CM, Verseghy D, Vasic R, Xue Y, Yamada T (2004) Regions of strong coupling between soil moisture and precipitation. Science 305:1138-1140. doi:10.1126/ science. 1100217

Koutsoyiannis D, Efstratiadis A, Georgakakos KP (2007) Uncertainty assessment of future hydroclimatic predictions: a comparison of probabilistic and scenario-based approaches. J Hydrometeorol 8:261-281. doi:10.1175/JHM576.1

Krakauer NY, Puma MJ, Cook BI (2013) Impacts of soil-aquifer heat and water fluxes on simulated global climate. Hydrol Earth Syst Sci 17:1963-1974. doi:10.5194/hess-17-1963-2013

Lawrence D, Vandecar K (2015) Effects of tropical deforestation on climate and agriculture. Nat Clim Change 5:27-36. doi:10.1038/ nclimate 2430

Lee JE, Oliveira RS, Dawson TE, Fung I (2005) Root functioning modifies seasonal climate. Proc Natl Acad Sci USA 102(49):17576-17581

Lee JE, Lintner BR, Neelin JD, Jiang X, Gentine P, Boyce CK, Fisher JB, Perron JT, Kubar TL, Lee J, Worden J (2012) Reduction of tropical land region precipitation variability via transpiration. Geophys Res Lett 39(19):L19704. doi:10.1029/2012GL053417

Lejeune Q, Davin EL, Guillod BP, Seneviratne SI (2014) Influence of amazonian deforestation on the future evolution of regional surface fluxes, circulation, surface temperature and precipitation. Clim Dyn. doi:10.1007/s00382-014-2203-8

Liang X, Xie Z, Huang M (2003) A new parameterization for surface and groundwater interactions and its impact on water budgets with the variable infiltration capacity (VIC) land surface model. J Geophys Res Atmos 108:8613. doi:10.1029/2002JD003090

Lo MH, Famiglietti JS (2010) The effect of water table dynamics on land surface hydrologic memory. J Geophys Res Atmos 115:D22118. doi:10.1029/2010JD014191

Lo MH, Famiglietti JS (2011) Precipitation response to land subsurface hydrologic processes in atmospheric general circulation model simulations. J Geophys Res Atmos 116:D05107. doi:10. 1029/2010JD015134 
Lo MH, Yeh PJF, Famiglietti JS (2008) Constraining water table depth simulations in a land surface model using estimated baseflow. Adv Water Resour 31:1552-1564. doi:10.1016/j. advwatres.2008.06.007

Lo MH, Famiglietti JS, Yeh PJF, Syed TH (2010) Improving parameter estimation and water table depth simulation in a land surface model using GRACE water storage and estimated baseflow data. Water Resour Res 46:W05517. doi:10.1029/2009WR007855

Miguez-Macho G, Fan Y (2012a) The role of the groundwater in the Amazon water cycle: 1 . Influence on seasonal streamflow, flooding and wetlands. J Geophys Res Atmos 117:D15113. doi:10.10 29/2012JD017539

Miguez-Macho G, Fan Y (2012b) The role of the groundwater in the Amazon water cycle: 2 . Influence on seasonal soil moisture and evapotranspiration. J Geophys Res Atmos 117:D15114. doi:10.1 029/2012JD017540

Murthi A, Bowman KP, Leung LR (2011) Simulations of precipitation using NRCM and comparisons with satellite observations and CAM: annual cycle. Clim Dyn 36(9-10):1659-1679

Negri AJ, Adler RF, Xu L, Surrat J (2004) The impact of Amazonian deforestation on dry season rainfall. J Clim 17:1306-1319

Niu GY, Yang ZL, Dickinson RE, Gulden LE (2005) A simple TOPMODEL-based runoff parameterization (SIMTOP) for use in global climate models. J Geophys Res 110:D21106. doi:10.102 9/2005JD006111

Niu GY, Yang ZL, Dickinson RE, Gulden LE, Su H (2007) Development of a simple groundwater model for use in climate models and evaluation with gravity recovery and climate experiment data. J Geophys Res Atmos 112:D07103. doi:10.1029/20 06JD007522

Oleson KW, Niu GY, Yang ZL, Lawrence DM, Thornton PE, Lawrence PJ, Stockli R, Dickinson RE, Bonan GB, Levis S, Dai A, Qian T (2008) Improvements to the community land model and their impact on the hydrological cycle. J Geophys Res Atmos 113:G01021. doi:10.1029/2007JG000563
Seager R, Naik N, Vecchi GA (2010) Thermodynamic and dynamic mechanisms for large-scale changes in the hydrological cycle in response to global warming. J Clim 23:4651-4668. doi:10.1175 /2010JCLI3655.1

Tan PH, Chou C, Tu JY (2008) Mechanisms of global warming impacts on robustness of tropical precipitation asymmetry. $\mathbf{J}$ Clim 21:5585-5602

Tapley BD, Bettadpur S, Watkins M, Reigber C (2004) The gravity recovery and climate experiment: mission overview and early results. Geophys Res Lett 31:L09607. doi:10.1029/200 4GL019920

van den Hurk B, Hirschi M, Schär C, Lenderink G, van Meijgaard E, van Ulden A, Rockel B, Hagemann S, Graham LP, Kjellström E, Jones R (2005) Soil control on runoff response to climate change in regional climate model simulations. J Clim 18:3536-3551

Wang J, Chagnon FJF, Williams ER, Betts AK, Renno NO, Machado LAT, Bisht G, Knox R, Brase RL (2009) Impact of deforestation in the amazon basin on cloud climatology. Proc Natl Acad Sci USA 106(10):3670-3674

Yeh PJF, Eltahir EAB (2005) Representation of water table dynamics in a land surface scheme. Part I: model development. J Clim 18:1861-1880. doi:10.1175/JCLI3330.1

Yeh PJF, Famiglietti JS (2009) Regional groundwater evapotranspiration in Illinois. J Hydrometeorol 10:464-478. doi:10.1175/2008 JHM1018.1

Yin L, Fu R, Shevliakova E, Dickinson RE (2013) How well can CMIP5 simulate precipitation and its controlling processes over tropical South America? Clim Dyn 41(11-12):3127-3143. doi:10.1007/s00382-012-1582-y

Yuan X, Xie Z, Zheng J, Tian X, Yang Z (2008) Effects of water table dynamics on regional climate: a case study over East Asian monsoon area. J Geophys Res Atmos 113:D21112. doi:10.1029/200 8JD010180 